\title{
Seminoma difuso em equino - relato de caso
}

Felipe Erison Medrado Rocha de Sousa', Lucas Troncarelli Rodrigues, Lucas Emanuel Ferreira Canuto, Antonio Fernando Leis Filho, Patrícia de Faria Lainetti, Roberto Rodrigues da Rosa Filho ${ }^{[b]}$, Patricia de Mello Papa, Frederico Ozanam Papa

${ }^{[a]}$ Faculdade de Medicina Veterinária e Zootecnia, Universidade Estadual Paulista (UNESP), Botucatu, SP, Brasil

[b] Universidade de São Paulo (USP), São Paulo, SP, Brasil

*Autor correspondente

e-mail: felipeerison@hotmail.com

\section{Resumo}

Neoplasias testiculares em equinos são raramente relatadas, provavelmente porque a maioria dos machos são orquiectomizados muito jovens e os testículos removidos não são examinados para a presença das alterações. As neoplasias testiculares mais frequentes em equinos são seminoma, teratoma, teratocarcinoma e carcinoma embrionário. 0 seminoma é comum em garanhões idosos e, ao contrário do homem e do cão, não tem nenhuma correlação com criptorquidismo, podendo ser uni ou bilateral. Histologicamente, são subdivididos nas formas intratubular ou difuso. Este estudo relata o caso de um equino, macho, da raça Mangalarga Marchador, de 19 anos, pesando 412 kg, atendido no setor de grandes animais do Departamento de Reprodução Animal e Radiologia Veterinária da FMVZ/UNESP, campus de Botucatu, apresentando histórico de aumento progressivo e contínuo do volume testicular direito há quatro meses, e com infertilidade nos últimos 12 meses. No exame clínico, o testículo direito apresentou-se com volume aumentado, consistência firme, forma ovoide, posição horizontal, sem alterações da mobilidade na bolsa testicular, indolor à palpação e sem aumento de temperatura. No exame ultrassonográfico do parênquima testicular foram identificadas áreas heterogêneas hiper e hipoecóicas circunscritas, caracterizando alterações no epitélio seminífero. Optou-se pela orquiectomia unilateral direita como tratamento e o testículo foi enviado em solução de formol a 10\% para a análise histopatológica. Macroscopicamente, verificou-se superfície irregular de coloração acastanhada com mesclas esbranquiçadas, parênquima heterogêneo de consistência flácida e presença de áreas exibindo múltiplas formações gelatinosas. Ao exame histopatológico, foram observadas células redondas e poligonais no parênquima, entremeadas ao estroma fibrovascular. As células neoplásicas apresentaram citoplasma distinto, eosinofílico, moderado, núcleo paracentral, cromatina densa ou frouxa e nucléolo indistinto. Notou-se moderada anisocitose e anisocariose, pleomorfismo discreto, intensa 
quantidade de células binucleadas e multinucleadas, com mitose atípica, sendo compatível com seminoma. Por ter como consequência infertilidade, seu diagnostico é fundamental para a vida reprodutiva futura do garanhão, visto que o testículo contralateral ao afetado continua produzindo espermatozoides e gerando descendentes. 0 aumento indolor do testículo que se desenvolve insidiosamente em garanhões mais velhos ( $\geq 10$ anos) é mais provável de ser causado por neoplasia do que por inflamação ou isquemia, no entanto, devem ser inspecionadas e descartadas outras causas de aumento da bolsa testicular, como torção do cordão espermático, orquite, epididimite, hidrocele, hematocele e herniação ou ruptura inguinal. 0 diagnóstico foi confirmado com base nos achados clínicos, ultrassonografia e histopatologia, concluindo tratar-se de um seminoma difuso unilateral em equino.

Palavras-chave: Neoplasia. Testículo. Equino. 